\title{
Mathematics: Art and Science
}

\section{A. Borel}

Published with the permission of Springer Science and Business Media: extracts from pp.9-17, The Mathematical Intelligencer, Vol. 5, No. 4, 1983, doi:10.1007/BF03026504.

The Mathematical Intelligencer Editor's note: Apart from some minor changes, the following article is a translation of the text of a lecture delivered, in German, at the Carl Friedrich von Siemens Stiftung, Munich, on May 7, 1981, and, in a slightly modified form, as the first of three "PauliVorlesungen”, on February 1, 1982, at the Federal School of Technology, Zurich.

The Intelligencer requested permission from the author to publish a translation of the text (translated by Kevin M. Lenzen). We supplied the translation which the author checked and modified. We wish to thank him for his considerable help in improving the original translation.

The German text of this lecture was published by the C. F. v. Siemens Stiftung (Mathematik: Kunst und Wissen- schaft, Themenreihe XXXIII). We are grateful for their permission to publish this English language version.

Ladies and Gentlemen,

It is a great honour to be invited to address you here but one which is fraught with difficulties. First, there is a rather natural reluctance for a practicing mathematician to philosophise about mathematics instead of just giving a mathematical talk. As an illustration, the English mathematician G. Hardy called it a "melancholy experience"to write about mathematics rather than just prove theorems! However, had I not surmounted that feeling, I wouldn't be here, so I need not dwell on it any more. More serious difficulties arise from the fact that there are mathematicians and non-mathematicians in the audience. Whether one should conclude from this that my talk is best suited for an empty audience is a 
question that every one of you will have answered within the next hour and therefore needs no further elaboration. The difficulty brought about by the presence of mathematicians here is that it makes me aware (almost painfully aware) that, in fact, everything about my topic has already been said, all arguments have already been presented and pros and cons argued: mathematics is only an art, or only a science, the queen of sciences, merely a servant of science or even art and science combined. The very subject of my address, in Latin Mathesis et Ars et Scientia Dicenda, appeared as the third topic in the defence of a dissertation in the year 1845. The opponent claimed it was only art but not science [1]. It has occasionally been maintained that mathematics is rather trivial, almost tautological, and as such certainly unworthy of being regarded either as art or as science [2]. Most arguments can be supported by many references to outstanding mathematicians. It is even possible sometimes, by selective citation, to attribute widely different opinions to one and the same mathematician. So I would like to emphasise at the outset that the professional mathematicians assembled here are unlikely to hear anything new.

If I turn to the non-mathematicians, however, I encounter a much bigger, almost opposite problem: my task is to say something about the essence, the nature, of mathematics. In so doing, however, I cannot assume that the object of my statements is common knowledge. Of course, I can presuppose a certain familiarity with Greek mathematics, Euclidean geometry, for example, perhaps the theory of conic sections, or even the rudiments of algebra or analytical geometry. But they have little to do with the object of present-day mathematical research. Starting from this more or less familiar ground, mathematicians have gone on to develop ever more abstract theories, which have less and less to do with everyday experience, even when they later find important applications in the natural sciences. The transition from one level of abstraction to the next has often been very difficult even for the best mathematicians and it represented, in their time, an extremely bold step. I couldn't possibly give a satisfactory survey of this accumulation of abstractions upon abstractions and of their applications in just a few minutes. Still, I would feel quite uncomfortable simply to philosophise about mathematics without saying anything specific on its contents. I would also like to have a small supply of examples at hand to be able to illustrate general statements about mathematics or the position of mathematics with respect to art and the natural sciences. I shall therefore attempt to describe, or at least to give an idea of, some such steps.

In doing so, I will not be able to define precisely all my terms and I don't expect full understanding by all. But that is not essential. What I want to communicate is really just a feeling for the nature of these transitions, perhaps even for their boldness and significance in the history of thought. And I promise not to spend any more than 20 minutes doing so.

A mathematician often aims for general solutions. He enjoys solving many special problems with a few gen- eral formulae. One can call this economy of thought or laziness. An age-old example is the solution to a seconddegree equation, say

$$
x^{2}+2 b x+c=0 .
$$

Here, $b$ and $c$ are given real numbers. We are looking for a real number $x$ that will satisfy this equation. For centuries, it has been known that $x$ can be expressed in terms of $b$ and $c$ by the formula

$$
x=-b \pm \sqrt{b^{2}-c} .
$$

If $b^{2}>c$, we can take the square root and get two solutions. If $b^{2}=c$ then $x=-b$ is said to be a double solution. If $b^{2}<c$, however, then we cannot take the square root and we maintain, at least at the beginning secondary school level, that there is no solution.

In the 16th century, similar formulas were devised for third- and even fourth-degree equations, such as the equation

$$
x^{3}+a x+b=0
$$

I won't write the formula out but it contains square roots and cube roots - so-called radicals. An extremely interesting phenomenon was discovered that came to be called the casus irreducibilis. If this equation has three distinct real solutions and we apply the formula, which in principle allows one to compute them, then we meet square roots of negative numbers; at the outset, these are meaningless. If we ignore the fact that they don't exist, however, and are not afraid to compute with them then they cancel out and we get the solutions, provided we carefully follow certain formal rules. In short, starting from the given real numbers $a, b$, we arrive at the sought for ones by using "nonreal numbers". The square roots of negative numbers were called "imaginary numbers"to distinguish them from the real numbers and controversies raged as to whether it was actually legitimate to use such nonreal numbers. Descartes, for example, did not want to have anything to do with them. Only around the year 1800 was a satisfactory solution - satisfactory for some at least - to this problem found. The real numbers are embedded in a bigger system consisting of the points of the plane, i.e. pairs of real numbers, between which one defines certain operations that have the same formal properties as the four basic operations in arithmetic. The real numbers are identified with the points on the horizontal axis and the square roots of negative numbers with those on the vertical axis. One then began to speak of complex (or imaginary) numbers. Formally, we can use these mathematical objects almost as easily as the real numbers and can obtain solutions that are sometimes real, sometimes complex. For the second-degree equation mentioned earlier, we can now say that there are two complex solutions if $b^{2}<c$.

To a certain extent, this is, of course, merely a convention but it wasn't easy to grant these complex numbers the same right to existence as real numbers and not to regard 
them as a mere tool for arriving at real numbers. There was no strict definition of real numbers back then but the close connection between mathematics and measurement or practical computation gave real numbers a certain reality, in spite of the difficulties with irrational and negative numbers. It wasn't the same with complex numbers, however. That was a step in an entirely new direction, bringing a purely intellectual creation to the fore. As mathematicians became used to this new step, they began to realise that many operations performed with functions, such as polynomials, trigonometric functions, etc., still made sense when complex values were accepted as arguments and as values. This marked the beginning of complex analysis or function theory. As early as 1811, the mathematician Gauss pointed out the necessity of devising such a theory for its own sake:

The point here is not practical utility; rather, for me, analysis is an independent science which would lose an extraordinary amount of beauty and roundness by discriminating against those fictitious quantities [3].

Apparently, even he did not foresee the practical relevance complex analysis was later to achieve, as in the theories of electricity or aerodynamics, for example.

But that is not the end of it. Allow me, if you will, to mention two further steps toward greater abstraction. Let us return to our second-degree equation. One can now say that it has, in general, two solutions that may be complex numbers. Similarly, an equation of the $n$-th degree has $n$ solutions if one accepts complex numbers. From the 16th century on, people wondered whether there was also a general formula that would express the solutions of an equation of degree at least five from the coefficients by means of radicals. It was finally proved to be impossible. One proof (chronologically the third) was given by the French mathematician E. Galois within the framework of a more general theory, which was not understood at the time and subsequently forgotten. Some 15 years later, his work was rediscovered and understood only with great difficulty by a very few, so new was his viewpoint. Given an equation, Galois considered a certain set of permutations of the roots and showed that certain properties of this set of permutations are decisive. That was the beginning of an independent study of such sets of permutations, which later came to be known as Galois groups. He showed that an equation is solvable by means of radicals only when the groups involved belong to a certain class: namely, the solvable groups, as they came to be called. The theorem mentioned earlier, regarding equations of degree at least five, is then a consequence of the fact that the group associated to a general equation of the $n$-th degree is solvable only when $n$ $=1,2,3,4$ [4]. The important properties of such groups, for instance to be solvable, are actually independent of the nature of the objects to be permuted and this led to the idea of an "abstract group" and to theorems of great significance, applicable in many areas of mathematics. But, for many years, this appeared to be nothing more than pure and very abstract mathematics. As a mathema- tician and a physicist were discussing the curriculum for physics at Princeton University around the year 1910, the physicist said they could no doubt leave out group theory, for it would never be applicable to physics [5]. Not 20 years later, three books on group theory and quantum mechanics appeared and, since then, groups have been fundamental in physics as well.

The following will serve as a final example. I said earlier that we can consider complex numbers to be points in the plane. An Irish mathematician, N.R. Hamilton, wondered whether one could define an analogue of the four basic operations among the points of three-dimensional space, thus forming an even more comprehensive number system. It took him about 10 years to find the answer: it is not possible in three-dimensional space but it is in four-dimensional space. We do not need to try to imagine just what four-dimensional space is here. It is simply a figure of speech for quadruples of real numbers instead of triples or pairs of real numbers. He called these new numbers quaternions. He did, however, have to do without one property of real or complex numbers, which, up until then, had been taken for granted: commutativity in multiplication, i.e. $a \times b=b \times a$. He also showed that calculus with quaternions had applications in the mathematical treatment of questions in physics and mechanics. Later, many other algebraic systems with a noncommutative product were defined, notably matrix algebras. This also appeared to be an entirely abstract form of mathematics, without connections to the outside world. In 1925, however, as Max Born was thinking about some new ideas of W. Heisenberg's, he discovered that the most appropriate formalism for expressing them was none other than matrix algebra, and this suggested that physical quantities be represented by means of algebraic objects that do not necessarily commute. This led to the uncertainty principle and was the beginning of matrix quantum mechanics and of the assignment of operators to physical quantities, which is at the basis of quantum mechanics [6].

With this last example, I shall conclude my attempts to describe some mathematical topics. The examples are, of course, extremely incomplete and not at all representative of all areas of mathematics. They do have two properties in common, however, which I would like to emphasise since they are valid in a great many cases. First of all, these developments lead in the direction of ever greater abstraction, further and further away from nature. Second, abstract theories developed for their own sake have found important applications in the natural sciences. The suitability of mathematics to the needs of the natural sciences is, in fact, astonishingly great (one physicist spoke once of the "unreasonable effectiveness of mathematics"[7]) and is worthy of a far more detailed discussion than I can afford to enter into here.

The transition to ever greater abstraction is not to be taken for granted, as you may have gathered from Gauss' quotation. Mathematics was originally developed for practical purposes such as bookkeeping, measurements and mechanics; even the great discoveries of the 17th century, such as infinitesimal and integral calculus, were, 
at first, primarily tools for solving problems in mechanics, astronomy and physics. The mathematician Euler, who was active in all areas of mathematics and its applications - including shipbuilding - also wrote papers on pure number theory and, more than once, felt the need to explain that it was as justified and important as more practically oriented work [8]. Mathematics was, from the very beginning, of course, a kind of idealisation but, for a long time, was not as far removed from reality or, more precisely, from our perception of reality as in the examples mentioned earlier. As mathematicians went further in this direction, they became increasingly aware that a mathematical concept has a right to existence as soon as it has been defined in a logically consistent manner, without necessarily having a connection with the physical world, and that they had the right to study it even when there seemed to be no practical applications at hand. In short, this led more and more to "Pure Mathematics"or "Mathematics for Its Own Sake".

But if one leaves out the controlling function of practical applicability, the question immediately arises as to how one can make value judgments. Surely not all concepts and theorems are equal; as in George Orwell's Animal Farm, some must be more so than others. Are there then internal criteria that can lead to a more or less objective hierarchy? You will notice that the same basic question can be asked about painting, music or art in general. It thus becomes a question of aesthetics. Indeed, a usual answer is that mathematics is, to a great extent, an art, an art whose development has been derived from, guided by and judged according to aesthetic criteria. For the layperson, it is often surprising to learn that one can speak of aesthetic criteria in so grim a discipline as mathematics. But this feeling is very strong for the mathematician, even though it is difficult to explain. What are the rules of this aesthetic? Wherein lies the beauty of a theorem, of a theory? Of course, there is no single answer that will satisfy all mathematicians but there is a surprising degree of agreement, to a far greater extent, I think, than exists in music or painting.

Without wishing to maintain that I can explain this fully, I would like to attempt to say a bit more about it later. At the moment, I shall content myself with the assertion that the analogy with art is one with which many mathematicians agree. For example, G. H. Hardy was of the opinion that if mathematics has any right to exist at all then it is only as art [9]. Our activity has much in common with that of an artist: a painter combines colours and forms, a musician tones, a poet words, and we combine ideas of a certain sort. The painter E. Degas wrote sonnets from time to time. Once, in a conversation with the poet S. Mallarmé, he complained that he found writing difficult even though he had many ideas, indeed an overabundance of ideas. Mallarmé answered that poems were made of words, not ideas [10]. We, on the other hand, work primarily with ideas.

This feeling of art becomes even stronger when one thinks of how a researcher works and progresses. One should not imagine that the mathematician operates entirely logically and systematically. He often gropes about in the dark, not knowing whether he should attempt to prove or disprove a certain proposition, and essential ideas often occur to him quite unexpectedly, without him even being able to see a clear and logical path leading to them from earlier considerations. Just as with composers and artists, one should speak of inspiration [11].

Other mathematicians, however, are opposed to this view and maintain that an involvement with mathematics without being guided by the needs of the natural sciences is dangerous and almost certainly leads to theories that may be quite subtle and may provide the mind with a peculiar pleasure but which represent a kind of intellectual mirror that is completely worthless from the standpoint of science or knowledge. For example, the mathematician J. von Neumann wrote in 1947:

As a mathematical discipline travels far from its empirical sources, or still more, if it is second and third generation only indirectly inspired by ideas coming from "reality", it is beset with very grave dangers. It becomes more and more purely aestheticizing, more and more purely l'art pour l'art ... there is a great danger that the subject will develop along the line of least resistance ... will separate into a multitude of insignificant branches...

In any event ... the only remedy seems to me to be the rejuvenating return to the source: the reinjection of more or less directly empirical ideas [12].

Still others have taken a more intermediate stance: they fully recognise the importance of the aesthetic side of mathematics but feel that it is dangerous to push mathematics for its own sake too far. Poincaré, for example, wrote:

In addition to this, it provides its disciples with pleasures similar to painting and music. They admire the delicate harmony of the numbers and the forms; they marvel when a new discovery opens up to them an unexpected vista; and does the joy that they feel not have an aesthetic character even if the senses are not involved at all? ...

For this reason, I do not hesitate to say that mathematics deserves to be cultivated for its own sake, and I mean the theories which cannot be applied to physics just as much as the others [13].

But a few pages further on, he returns to this comparison and adds:

If I may be allowed to continue my comparison with the fine arts then the pure mathematician who would forget the existence of the outside world could be likened to the painter who knew how to combine colours and forms harmoniously but who lacked models. His creative power would soon be exhausted [14].

This denial of the possibility of abstract painting strikes me as especially noteworthy since we are in Munich, where, not much later, an artist would concern himself 
quite deeply with this question (namely, Wassily Kandinsky). It was sometime in the first decade of this century that he suddenly felt, after looking at one of his own canvases, that the subject can be detrimental to the painting in that it may be an obstacle to direct access to forms and colours: that is, to the actual artistic qualities of the work itself. But, as he wrote later [15], "a frightening gap"(eine erschreckende Tiefe) and a mass of questions confronted him, the most important of which was: "What should replace the missing subject?"Kandinsky was fully aware of the danger of ornamentation, of a purely decorative art, and wanted to avoid it at all costs. Contrary to Poincaré, however, he did not conclude that painting without a real subject had to be fruitless. In fact, he even developed a theory of the "inner necessity" and "intellectual content" of a painting. Since about 1910, as you know, he and other painters in increasing numbers have dedicated themselves to so-called abstract or pure painting, which has little or nothing to do with nature.

If one does not want to admit an analogous possibility for mathematics, however, then one will be led to a conception of mathematics that I would like to summarise as follows. On the one hand, it is a science because its main goal is to serve the natural sciences and technology. This goal is actually at the origin of mathematics and is constantly a wellspring of problems. On the other hand, it is an art because it is primarily a creation of the mind and progress is achieved by intellectual means, many of which issue from the depths of the human mind and for which aesthetic criteria are the final arbiters. But this intellectual freedom to move in a world of pure thought must be governed, to some extent, by possible applications in the natural sciences.

However, this view is really too narrow; in particular, the final clause is too limiting and many mathematicians have insisted on complete freedom of activity. First of all, as has already been pointed out, many areas of mathematics that have proved important for applications would not have been developed at all if one had insisted on applicability from the beginning. In spite of the above quotation, von Neumann himself pointed this out in a later lecture:

But still a large part of mathematics which became useful developed with absolutely no desire to be useful, and in a situation where nobody could possibly know in what area it would become useful: and there were no general indications that it even would be so ... This is true of all science. Successes were largely due to forgetting completely about what one ultimately wanted, or whether one wanted anything ultimately, in refusing to investigate things which profit, and in relying solely on guidance by criteria of intellectual elegance...

And I think it extremely instructive to watch the role of science in everyday life, and to note how in this area the principle of laissez faire has led to strange and wonderful results [16].

Secondly, and for me more importantly, there are areas of pure mathematics which have found little or no application outside mathematics but which one cannot help viewing as great achievements. I am thinking, for example, of the theory of algebraic numbers, class field theory, automorphic functions, transfinite numbers, etc.

Let us return to the comparison with painting once again and take as "subject"the problems that are drawn from the physical world. Then, we see that we have painting drawn from nature as well as pure or abstract painting.

This comparison is, however, not yet entirely satisfactory, for such a description of mathematics would not encompass all its essential aspects, in particular its coherence and unity. Indeed, mathematics displays a coherence that I feel is much greater than in art. As a testimony to this, note that the same theorem is often proved independently by mathematicians living in widely separated locations or that a considerable number of papers have two, sometimes more, authors. It can also happen that parts of mathematics that have been developed completely independently of one another suddenly demonstrate deep connections under the impact of new insights. Mathematics is, to a great extent, a collective undertaking. Simplifications and unifications maintain the balance with unending development and expansion; they display again and again a remarkable unity even though mathematics is far too large to be mastered by a single individual.

I think it would be difficult to account fully for this by appealing solely to the criteria mentioned earlier: namely, subjective ones like intellectual elegance and beauty, and consideration of the needs of natural sciences and technology. One is then led to ask whether there are criteria or guidelines other than those. In my opinion, this is the case and I would now like to complete the earlier description of mathematics by looking at it from a third standpoint and adding another essential element to it. In preparation for this, I would like to digress, or at least apparently digress, and take up the question: 'Does mathematics have an existence of its own? Do we create mathematics or do we gradually discover theories which exist somewhere independently of us?' If this is so, where is this mathematical reality located?

It is, of course, not absolutely clear that such a question is really meaningful. But this feeling - that mathematics somehow, somewhere, pre-exists - is widespread. It was expressed quite sharply, for example, by G.H. Hardy:

I believe that mathematical reality lies outside us, that our function is to discover or observe it, and that the theorems which we prove, and which we describe grandiloquently as our "creations", are simply our notes of our observations. This view has been held, in one form or another, by many philosophers of high reputation, from Plato onwards... [17].\}

If one is a believer then one will see this pre-existent mathematical reality in God. This was actually the belief of Hermite, who once said: 
There exists, if I am not mistaken, an entire world which is the totality of mathematical truths, to which we have access only with our mind, just as a world of physical reality exists, the one like the other independent of ourselves, both of divine creation [18].

It wasn't too long ago that a colleague explained in an introductory lecture that the following question had occupied him for years: 'Why has God created the exceptional series?'

But a reference to divine origin would hardly satisfy the nonbeliever. Many do, however, have a vague feeling that mathematics exists somewhere, even though, when they think about it, they cannot escape the conclusion that mathematics is exclusively a human creation.

Such questions can be asked of many other concepts such as state, moral values, religion, etc., and would probably be worthy of consideration all by themselves. But for want of time and competence, I shall have to content myself with a short and possibly oversimplified answer to this apparent dilemma by agreeing with the thesis that we tend to posit existence on all those things that belong to a civilization or culture in that we share them with other people and can exchange thoughts about them. Something becomes objective (as opposed to "subjective") as soon as we are convinced that it exists in the minds of others in the same form as it does in ours and that we can think about it and discuss it together [19]. Because the language of mathematics is so precise, it is ideally suited to defining concepts for which such a consensus exists. In my opinion, that is sufficient to provide us with a \{lit feeling\} of an objective existence, of a reality of mathematics similar to that mentioned by Hardy and Hermite above, regardless of whether it has another origin, as Hardy and Hermite maintain. One could speculate forever on this last point, of course, but that is actually irrelevant to the continuation of this discussion.

Before I elaborate on this, I would like to note that similar thoughts about our conception of physical reality have been expressed. For example, Poincaré wrote:

Our guarantee of the objectivity of the world in which we live is the fact that we share this world with other sentient beings...

That is therefore the first requirement of objectivity: that which is objective must be common to more than one spirit and as a result be transmittable from one to the other... [20]

\section{And Einstein:}

By the aid of speech, different individuals can, to a certain extent, compare their experiences. In this way, it is shown that certain sense perceptions of different individuals correspond to each other, while for other sense perceptions no such correspondence can be established. We are accustomed to regard as real those sense perceptions which are common to different individuals, and which therefore are, in a measure, impersonal [21].
Now back to mathematics. Mathematicians share an intellectual reality: a gigantic number of mathematical ideas, objects whose properties are partly known and partly unknown, theories, theorems, solved and unsolved problems, which they study with mental tools. These problems and ideas are partially suggested by the physical world; primarily, however, they arise from purely mathematical considerations (such as groups or quaternions to go back to my earlier examples). This totality, although stemming from the human mind, appears to us to be a natural science in the normal sense, such as physics or biology, and is for us just as concrete. I would actually maintain that mathematics not only has a theoretical side but also an experimental one. The former is clear: we strive for general theorems, principles, proofs and methods. That is the theory. But, in the beginning, one often has no idea of what to expect and how to continue, and one gains understanding and intuition through experimentation, that is, through the study of special cases. First, one hopes to be led in this way to a sensible conjecture and, second, perhaps to stumble upon an idea that will lead to a general proof. It can also happen, of course, that certain special cases are of great interest in themselves. That is the experimental side. The fact that we operate with intellectual objects more than with real objects and laboratory equipment is actually not important. The feeling that mathematics is, in this sense, an experimental science is also not new.

Hermite, for example, wrote to L. Königsberger around 1880:

The feeling expressed at that point in your letter where you say to me: "The more I think about all these things, the more I come to realise that mathematics is an experimental science like all other sciences."This feeling, I say, is also my feeling [22].

Traditionally, these experiments are carried out in one's head (or with pen and paper) and for this reason I have spoken of mental tools. I should add, however, that for about 20 years, real apparatuses, namely, electronic computers, have been playing an increasing role. They have actually given this experimental side of mathematics a new dimension. This has advanced to the extent that one can already see important, reciprocal and fascinating interactions between computer science and pure mathematics.

The word "science"in my title now takes a broader meaning: it refers not only to the natural sciences, as it did earlier, but also - and this to a much greater extent - to the conception of mathematics itself as an experimental and theoretical science or, I would venture to say, as a mental natural science, as a natural science of the intellect, whose objects and modes of investigations are all creations of the mind.

This makes it somewhat easier for me to speak of motivation and aesthetics. If one does not want to take applications in the natural sciences as a yardstick, one is still not thrown back upon mere intellectual elegance. There still remain almost practical criteria: namely, appli- 
cability in mathematics itself. The consideration of this mathematical reality, the open problems, the structure, needs and connections among various areas, already indicates possibly fruitful, valuable directions and allows the mathematician to orient himself and attach relative values to problems as well as to theories. Often a test for the value of a new theory is whether it can solve old problems. De facto, this limits the freedom of a mathematician, in a way which is comparable to the constraints imposed on a physicist, who after all doesn't choose at random the phenomena for which he wants to construct a theory or to devise experiments. Many examples show that mathematicians have often been able to foresee how certain areas of mathematics will develop and which problems should be taken up and probably quickly solved. Rather often, statements about the future of mathematics have proved true. Such predictions are not perfect but they are successful enough to indicate a difference from art. Analogous relatively successful forecasts about the future of painting, for example, hardly exist at all.

I don't want to go too far in this. However, I suggested the concept of mathematics as a mental natural science as one of three elements, not as the whole. On the one hand, I don't want to overlook the importance of the interactions between mathematics and the natural sciences. First, it is a common saying that all disciplines in the natural sciences must strive for a mathematical formulation and treatment - indeed, that a discipline achieves the status of a science only when this has been carried out. Thus, it is surely important that mathematicians try to help in this way. Second, it is doubtless a great achievement to formulate and treat complicated phenomena mathematically, and the new problems that are thereby introduced represent an enrichment for mathematics. One need only think of probability. I only mean that it is simply not necessary to put the idea of applicability in the foreground in order to do valuable mathematics. The history of mathematics shows that many outstanding achievements came from mathematicians who weren't thinking at all about external applications and who were led by purely mathematical considerations. And as has already been mentioned and illustrated, these contributions often found important applications in the natural sciences or in engineering, often in completely unforeseen ways.

On the other hand, I don't want to say that one can foresee everything completely rationally. Actually, this isn't the case even in the natural sciences, especially since one often does not know in advance which experiments will prove interesting. Outstanding mathematicians have also been wrong and have sometimes, precisely in the name of applicability within mathematics, termed fruitless, idle or even dangerous, new ideas that later proved fundamental. The freedom not to consider practical applications, which von Neumann demanded for science as a whole, must also be demanded within mathematics.

One could object that this analogy between mathematics and the natural sciences overlooks one essential difference: in the natural sciences or in technology, one often encounters problems that one has to solve in order to advance at all. In the world of mathematical thought, one has still de jure the freedom to put aside apparently unsolvable, overly difficult problems and turn to other, more manageable ones and maybe, in fact, follow the path of least resistance, just as von Neumann had feared. Wouldn't that be a temptation for a mathematician who defines mathematics as "the art of finding problems that one can solve"? Interestingly enough, I heard this definition from a mathematician whose works are especially remarkable because they treated so many problems which seemed quite special at the time but which later proved fundamental and whose solutions opened up new paths, namely, Heinz Hopf.

It cannot be denied, however, that sometimes paths of least resistance are indeed followed, leading to trivial or meaningless work. It can also happen that a successful school later falls into a sterile period and then even, at worst, exerts a harmful influence. Remarkably enough, however, an antidote always comes along, a reaction that eliminates these mistaken paths and fruitless directions. Up until now, mathematics has always been able to overcome such growth diseases and I am convinced that it will always do so, as long as there are so many talented mathematicians. It is very odd, however. Many of us have this feeling of a unity in mathematics but it is dangerous to prescribe overly precise guidelines in the name of our conception of it. It is more important that freedom reigns, despite occasional misuse. Why this is so successful cannot be fully explained. If one thinks of Hopf, for example, one can, to a certain extent, see rational criteria in his choice of problems: they were, for instance, often the first special cases of a general problem for which known methods of proof were not applicable. He was, of course, aware of this. But that doesn't explain everything. He probably didn't always foresee how influential his work would become; and, most likely, he did not worry about it. It is simply a part of the talent of a mathematician to be drawn to "good" problems, i.e. to problems that turn out to be significant later, even if it is not obvious at the time he takes them up. The mathematician is led to this partly by rational, scientific observations and partly by sheer curiosity, instinct, intuition or purely aesthetic considerations. Which brings me to my final subject: the aesthetic feeling in mathematics.

I have already mentioned the idea of mathematics as an art, a poetry of ideas. With that as a starting point, one would conclude that, in order for one to appreciate mathematics, to enjoy it, one needs a unique feeling for intellectual elegance and beauty of ideas in a very special world of thought. It is not surprising that this can hardly be shared with non-mathematicians: our poems are written in a highly specialised language, the mathematical language; although it is expressed in many of the more familiar languages, it is nevertheless unique and translatable into no other language; and unfortunately, these poems can only be understood in the original. The resemblance to an art is clear. One must also have a certain education for the appreciation of music or painting, which is to say one must learn a certain language.

I have long agreed with such opinions and analogies. Without changing my fundamental position with regard 
to mathematics, I would nonetheless like to reformulate them somewhat in the direction of my previous statements. I believe that our aesthetics are not always so pure and esoteric but also include a few more earthly yardsticks such as meaning, consequences, applicability, usefulness - but within the mathematical science. Our judgment of a theorem, a theory or a proof is also influenced by this but it is often simply equated to the aesthetic. I would like to try to explain this using Galois' theory mentioned earlier. This theory is generally treasured as one of the most beautiful chapters in mathematics. Why? First, it solved a very old and, at that time, most important question about equations. Second, it is an extremely comprehensive theory that goes far beyond the original question of solvability by radicals. Third, it is based on only a few principles of great elegance and simplicity, which are formulated within a new framework with new concepts that demonstrate the greatest originality. Fourth, these new viewpoints and concepts, especially the concept of a group, opened new paths and had a lasting influence on the whole of mathematics.

You will notice that of these four points only the third is a truly aesthetic judgment, and one about which one can have one's own opinion only when one understands the technical details of the theory. The others have a different character. One could make similar statements about theories in any natural science. They have a greater objective content, and a mathematician can have his own opinion about them even if he doesn't fully grasp the technical details of the theory. For the purpose of this discussion, I have separated these four elements but normally I would not always do so explicitly, and all four contribute to the impression of beauty. I do think that, in this respect, this example is fairly typical: what we describe as aesthetic is actually often a fusion of different views. For example, I would naturally find a method of proof more beautiful if it found new and unexpected applications, although the method itself hadn't changed. It may have become more important but in and of itself not more beautiful. Since all this takes place within mathematics itself, it will hardly help the non-mathematician penetrate our aesthetic world. I hope, however, that it will help him find more plausible the fact that our so-called aesthetic judgments display a greater consensus than in art, a consensus that goes far beyond geographical and chronological limitations. In any case, I regard this as being a major factor. But once again, I must avoid taking this too far. It is a question of degree, not an absolute difference. An aesthetic judgment on the work of a composer or a painter also draws on external factors such as influence, predecessors and the position of the work with relation to other works, even if it is to a lesser extent. On the other hand, there are differences of opinion and fluctuations in time in the evaluation of mathematical works, though not to such a strong degree, I would add. All these nuances need a good deal of explanation, which I cannot go into here for lack of time.

In the limited amount of time at my disposal, it would, of course, be easier to make only sweeping short state- ments about mathematics. But unfortunately, or fortunately, just as in other human undertakings to which many people have contributed over many centuries, mathematics refuses to let itself be described by just a few simple formulas. Almost every general statement about mathematics has to be qualified somehow. One exception, perhaps the only one, might be this statement itself. I hope I have, at least, given the impression that mathematics is an extremely complex creation, which displays so many essential traits in common with art and experimental and theoretical sciences that it has to be regarded as all three at the same time, and thus must be differentiated from all three as well.

I am aware that I have raised more questions than I have answered, treated too briefly those I have discussed and not even touched upon some important ones, such as the value of this creation. One can, of course, point to innumerable applications in the natural sciences and in engineering, many of which have a great influence on our daily life, thereby establishing a social right to existence for mathematics. But I must confess that, as a pure mathematician, I am more interested in an assessment of mathematics in itself. The contributions of the various mathematicians meld into an enormous intellectual construct, which, in my opinion, represents an impressive testimony to the power of human thinking. The mathematician Jacobi once wrote that "the only purpose of science is to honour the human mind"[23]. I believe that this creation does indeed do the human mind great honour.

The Institute for Advanced Study Princeton, New Jersey 08540

\section{Notes}

1 The dissertation was by L. Kronecker, see Werke, 5 Vol., Teubner, Leipzig, 1895-1930, Vol. 1, p. 73. The opponent was G. Eisenstein. The source I am aware of because the name and the opinion of the opponent is a footnote by E. Lampe to a lecture by P. du BoisReymond, "Was will die Mathematik und was will der Mathematiker?", published posthumously by E. Lampe in Jahresbericht der Deutschen Mathematiker-Vereinigung 19 (1910), 190-198.

2 For a discussion of a number of such opinions, see A. Pringsheim, "Ueber den Wert und angeblichen Unwert der Mathematik", Jahresbericht der Deutschen Mathematiker-Vereinigung 13 (1904), 357-382.

3 Letter to F. W. Bessel, 18 November 1811. See G. F. Auwers Verlag, Briefwechsel zwischen Gauss und Bessel, Leipzig 1880, p. 156.

4 Actually, the beginnings of group theory can already be traced to some earlier work, notably by Lagrange, which was, in part, familiar to Galois. The latter's standpoint was, however, so general and abstract and, in addition, so sketchily described that it was assimilated only slowly. For historical information on the theory of equations and the beginnings of group theory, see, for example, N. Bourbaki, Eléments d'histoire des mathématiques, Hermann ed., Paris, 1969, third and fifth articles.

5 F.J. Dyson, "Mathematics in the physical sciences", Scientific American 211, September (1964), 129-146.

6 See B.L. van der Waerden's historical introduction in "Sources in Quantum Mechanics", Classics of Science, Vol. 5, Dover Publications, New York, 1967, especially pp. 36-38. Also see Dirac's remarks on the introduction of non-commutativity in quantum mechanics in loc. cit. [7]. 
7 E. P. Wigner, "The unreasonable effectiveness of mathematics in the natural sciences", Communications on Pure and Applied Mathematics 13 (1960), 1-14.

Among the many aspects of this interaction, the one that appears most remarkable to me is that the mathematical formalism sometimes leads to basic, new and purely physical ideas. One well known example is the discovery of the positron. In 1928, P.A.M. Dirac set up quantum mechanic relativistic equations for the movement of the electron. These equations also allowed a solution with the same mass as the electron but with the opposite electrical charge. All attempts to explain these solutions satisfactorily, or to eliminate them by some suitable modification of the equation, were unsuccessful. This led Dirac eventually to conjecture the existence of a particle with the necessary properties, which was later established by Anderson. For this, see P. A. M. Dirac, "The development of quantum theory"(J. R. Oppenheimer Memorial Prize acceptance speech), Gordon and Breach, New York, 1971.

A newer and even more comprehensive example would be the use of irreducible representations of the special unitary group SU(3) in three complex variables, which led to the so-called "eightfold way". One of the first successes of this theory was quite striking, namely, the discovery of the particle $\Omega^{-}$: nine baryons were assigned, through consideration of two of their characteristic quantum numbers, to nine points of a very specific mathematical configuration consisting of 10 points in a plane [the 10 weights of an irreducible 10-dimensional representation of SU(3)]; this led M. Gell'man to conjecture that there should also be a particle corresponding to the tenth point, which would then possess certain well-defined properties. Such a particle was observed some two years later. A further development along these lines led to the theory of "quarks". For the beginnings of this theory, see F.J. Dyson, loc. cit. [5] and M. Gell'man and Y. Ne'eman, The Eightfold Way, W.A. Benjamin, New York, 1964.

8 See a number of papers in L. Euler's Opera Omnia, especially I.2, $62-63,285,461,576 ;$ I.3, 5.2. I want to thank A. Weil for pointing this out to me. Here is an example (translated from Latin by Weil), loc. cit. pp. 62-63, published in 1747:

"Nor is the author disturbed by the authority of the greatest mathematicians when they sometimes pronounce that number theory is altogether useless and does not deserve investigation. In the first place, knowledge is always good in itself, even when it seems to be far removed from common use. Secondly, all the aspects of the truth which are accessible to our mind are so closely related to one another that we dare not reject any of them as being altogether useless. Moreover, even if the proof of some proposition does not appear to have any present use, it usually turns out that the method by which this problem has been solved opens the way to the discovery of more useful results.

"Consequently, the present author considers that he has by no means wasted his time and effort in attempting to prove various theorems concerning integers and their divisors. Actually, far from being useless, this theory is of no little use even in analysis. Moreover, there is little doubt that the method used here by the author will turn out to be of no small value in other investigations of greater import."

9 G.H. Hardy, A Mathematician's Apology, Cambridge University Press, 1940; new printing with a foreword by C.P. Snow, pp. 139-140.

10 P. Valery, Degas, danse, dessin, A. Vollard éd., Paris, 1936; CEuvres II, La Pléiade, Gallimard éd., Paris, 1966, pp. 1163-1240, especially pp. 1207-1209.

11 The following excerpt from a letter from C.F. Gauss to Olbers, written on 3 September 1805, shortly after Gauss had solved a problem (the "sign of the Gaussian Sums") he had been working on for years, can serve as an example:
"Finally, just a few days ago, success - but not as a result of my laborious search but only by the grace of God I would say. Just as it is when lightning strikes, the puzzle was solved; I myself would not be able to show the threads which connect that which I knew before, that with which I had made my last attempt, and that by which it succeeded."See Gauss, Gesammelte Werke, Vol. 10, , pp. 24-25. Here one must also mention H. Poincaré's description of some of his fundamental discoveries on automorphic functions. H. Poincaré, "L'invention mathematique" in Science et Méthode, E. Flammarion éd., Paris, 1908, Chap. III.

12 J. v. Neumann, "The mathematician" in Robert B. Heywood, The Works of the Mind, University of Chicago Press, 1947, pp. 180-187. Collected Works, 6 Vol., Pergamon, New York, 1961, Vol. I, pp. 1-9.

13 H. Poincaré, La Valeur de la Science, E. Flammarion, Paris, 1905, Chap. 5, p. 139. Actually, this chapter is the printed version of a lecture that Poincaré delivered at the First International Congress of Mathematicians, Zurich, 1897.

14 Loc. cit. [13], p. 147.

15 W. Kandinsky, Rückblick 1901-1913, H. Walden ed., 1913. New printing by W. Klein Verlag, Baden-Baden, 1955. See pp. 20-21.

16 J.v. Neumann, "The role of mathematics in the science and in society", address to Princeton Graduate Alumni, June 1954. See Collected Works, 6 Vol., Pergamon, New York, 1961, Vol. VI, pp. 477-490.

17 See G.H. Hardy, loc. cit. [9], pp. 123-124.

18 G. Darboux, "La vie et l'Euvre de Charles Hermite", Revue du mois, 10 January 1906, p. 46.

19 See L. White, "The locus of mathematical reality: An anthropological footnote", Philosophy of Science 14 (1947), 189303; also in J.R. Newman, The World of Mathematics, 4 Vol., Simon and Schuster, New York, 1956, Vol. 4, pp. 2348-2364.

20 H. Poincaré, loc. cit. [13], p. 262.

21 A. Einstein, Vier Vorlesungen über Relativitätstheorie, held in May 1921 at Princeton University, Fr. Vieweg und Sohn, Braunschweig, 1922, p. 1. English translation in: The Meaning of Relativity, Princeton University Press, Princeton, 1945.

22 See L. Königsberger, "Die Mathematik eine Geistes- oder Naturwissenschaft?", Jahresbericht der Deutschen Mathematiker-Vereinigung 23 (1914), 1-12.

23 In a letter of 2 July 1830 to A.M. Legendre, see C.G.J. Jacobi, Gesammelte Werke, G. Riemer, Berlin, 1881-1891, Vol. 1, pp. 453-455. Since this statement is sometimes misquoted, we prefer to give here its original context:

"Mais M. Poisson n'aurait pas dû reproduire dans son rapport une phrase peu adroite de feu M. Fourier, où ce dernier nous fait des reproches, à Abel et à moi, de ne pas nous être occupés de préférence du mouvement de la chaleur. II est vrai que M. Fourier avait l'opinion que le but principal des mathématiques était l'utilité publique et l'explication des phénomènes naturels; mais un philosophe comme lui aurait dû savoir que le but unique de la science, c'est l'honneur de l'esprit humain et que sous ce titre une question de nombres vaut autant qu'une question du système du monde." 